\title{
Staffing Models for the ICU: Open, Closed, MD, NP, or Telemedicine?
}

\author{
Jacob T. Gutsche $\cdot$ Jesse M. Raiten
}

Published online: 12 February 2013

(C) Springer Science + Business Media New York 2013

\begin{abstract}
Intensive care is an expensive endeavor, estimated to account for more than $4 \%$ of health care expenditure in the USA. The cost of critical care services is expected to increase as the population ages and requires more ICU-level care. Intensivists are physicians specially trained in the care of critically ill patients. A large body of evidence indicates that involvement of intensivists in the care of critically ill patients improves clinical outcome and limits costs. Currently, only about one third of critically ill patients benefit from the care of a dedicated intensivist. This number is expected to increase because the Leapfrog Group, an organization representing a large consortium of health care purchasers, is working to financially reward hospitals with dedicated intensivist staffing. Several different models of critical care delivery exist, and there continues to be debate about the best way to provide care. In addition, a shortage of intensivists has led to a search for the best way to provide off-hours critical care coverage. This article reviews the evidence regarding intensivistdriven care, nighttime coverage, and telemedicine.
\end{abstract}

Keywords Intensive care unit - Intensivist - Leapfrog Group · Critical care physician · Telemedicine

J. T. Gutsche $(\triangle)$ · J. M. Raiten

Department of Anesthesiology and Critical Care, Perelman

School of Medicine, University of Pennsylvania, 3400 Spruce

Street, Dulles 6, Philadelphia, PA 19104, USA

e-mail: jacob.gutsche@uphs.upenn.edu

J. M. Raiten

e-mail: j.raiten@gmail.com

\section{Introduction}

The origin of the intensive care unit (ICU) emerged from an appreciation that critically ill patients benefit when clustered together in a defined area of the hospital. Throughout history there are multiple examples of units which were strategically designed to place acutely ill groups of patients in close proximity to the personnel and resources required for optimal care. The first recognized ICU consisted of four beds for monitoring postoperative neurosurgical patients at the Johns Hopkins Hospital in Baltimore [1]. This "unit" housed patients for the first $24 \mathrm{~h}$ after craniotomy and critically ill neurosurgery patients. During World War I and Word War II, shock wards were established to resuscitate injured soldiers [2]. In the 1950s, the development and use of mechanical ventilation led to the widespread development of respiratory care units across the country. In the same fashion, ICUs evolved to care for sick patients to allow efficient access to caregivers. More recently, superspecialized ICUs have been developed which cater for patients with specific medical and surgical conditions. ICUs are now recognized as an efficient way to care for our sickest patients. Today, ICUs share a common delivery model, which includes:

1. Specialized monitoring and therapeutic capabilities

2. A designated space

3. Resources to provide continual patient care

4. Appropriate nurse-to-patient ratios

5. Specialized personnel

ICUs are distinguished by a high nurse-to-patient ratio, usually $1: 2$ or less, but physician staffing in ICUs has not been standardized. It is recognized that critically ill patients consume a high proportion of medical resources, accounting for $20 \%$ of hospital costs and $15 \%$ of hospital days in the 
USA $[3,4 \bullet]$. In total, critical care medicine is estimated to account for almost $1 \%$ of the gross domestic product [5]. Demand for improvements in patient outcomes, coupled with increasing pressure to decrease the cost of medical care, has encouraged research into the optimal physician staffing model to treat critically ill patients. As intensivists are physicians trained to manage critical illness, including sepsis, acute respiratory failure and hemodynamic instability, multiple studies have shown an association between intensivist-driven patient care and a reduction in ICU costs, hospital/ICU lengths of stay (LOS), and hospital/ICU mortality [6-10].

\section{Defining an Intensivist}

To answer the question of who should take care of critically ill patients, it is important to understand the definition of an intensivist. An intensivist is a physician who specializes in the pathophysiology of the critically ill. In a sense, intensivists are the primary care physicians of the ICU, coordinating the tests, treatments, and consultant recommendations for patients who experience multiorgan system failure. Intensivists are experts in implementing preventative therapies for diseases that are more commonly seen in the critically ill [11, 12]. In addition, intensivists are often asked to oversee ICU bed management, design clinical care guidelines, and make decisions about the purchase and use of equipment. In 1992, the Society of Critical Care Medicine (SCCM) published guidelines for the definition of an intensivist and the role of the intensivist in the ICU.

According to these guidelines, the definition of an intensivist may be summarized as:

1. A physician board-certified in the subspecialty of critical care medicine after completing an Accreditation Council for Graduate Medical Education approved training program or one who has equivalent qualifications

2. A physician who devotes more than $50 \%$ of professional practice time to critical care medicine and participates in a unit-based 24/7 coverage model

3. A physician who has the ability to perform critical care procedures, including

(a) Tracheal intubation and ventilator management

(b) Catheter placement for venous access and hemodynamic management

(c) Pacing wire placement

(d) Cardiopulmonary resuscitation

(e) Tube thoracotomy

The Leapfrog Group, a consortium of large corporations and public agencies formed to advance improvements in medical care quality and safety, has attempted to clarify the role of an intensivist [13]. This group was formed after a report from the Institute of Medicine stated that 98,000 Americans die each year from preventable medical errors $[14,15]$. The Leapfrog Group explicitly states that an intensivist should manage or comanage ICU patients and also defines the availability of intensivists within the ICU and their role in care as follows:

1. All ICU patients are managed or comanaged by physicians certified in critical care.

2. Intensivists are present in the ICU (on-site or available by telemedicine) for a minimum of 8 daylight hours per day, 7 days per week.

3. Intensivists are available to return ICU pages within 5 min.

4. Patients can rely on a physician or nonphysician "effector" who is in the hospital and can reach the patient within $5 \mathrm{~min}$.

In the USA, critical care is considered a subspecialty of several fields, including anesthesiology, surgery, pediatrics, internal medicine, neurology, neurosurgery, and emergency medicine. The critical care training within each specialty is not uniform, and it is recognized that subspecialty ICUs may require intensivists with a thorough understanding of the problems common to a particular patient subset [16॰]. For example, a cardiac surgery ICU may have patients with cardiovascular complications, including heart failure, ischemia, and arrhythmias. The interventions may include sophisticated treatments such as intra-aortic balloon pumps, ventricular assist devices, and complex vasoactive medication management. The importance of having an intensivist with a thorough understanding of cardiac physiology and pathophysiology cannot be overstated.

\section{Open Versus Closed ICU}

The question of how to staff ICUs is a problem unique to the USA, as ICUs in the rest of the developed world are generally closed or mandatory intensivist consultation units [17]. In the USA, the quality of care and patient outcomes appear to differ widely between ICUs across hospitals [18, 19]. Differences in ICU staffing models may explain some of these differences in outcome.

To understand the literature addressing ICU staffing, it is necessary to understand the terminology used to describe the organization of patient care responsibilities (see Table 1). Broadly, ICUs may be divided into open or closed units [20]. In the closed unit model, the intensivist is responsible for all aspects of the patient's care, including ICU admission, discharge, and clinical management. In the open unit model, the primary attending is responsible for 
Table 1 Terminology

\begin{tabular}{ll}
\hline Term & Definition \\
\hline Closed ICU & $\begin{array}{c}\text { An intensivist is primarily responsible for } \\
\text { full-time ICU care } \\
\text { Effector }\end{array}$ \\
& $\begin{array}{c}\text { A nonintensivist physician or allied health } \\
\text { care provider trained to recognize and } \\
\text { treat acute decompensation in critically } \\
\text { ill patients } \\
\text { An ICU staffing model which includes } \\
\text { High-intensity staffing } \\
\text { mandatory intensivist consultation or a } \\
\text { closed ICU } \\
\text { Intensivist } \\
\text { A physician who specializes in managing } \\
\text { the care of critically ill patients } \\
\text { A large consortium of health care } \\
\text { purchasers and public agencies working } \\
\text { to improve health care using recognition } \\
\text { and rewards } \\
\text { An ICU staffing model which includes } \\
\text { elective intensivist consultation or no } \\
\text { intensivist consultation } \\
\text { A patient's primary physician is } \\
\text { responsible for full-time ICU care. In } \\
\text { many open ICUs the primary physician } \\
\text { may consult an intensivist }\end{array}$ \\
Open ICU &
\end{tabular}

$I C U$ intensive care unit

individual patient clinical management, and intensivist involvement ranges from mandatory consultation to no involvement at all. Many of the early studies attempting to link improved patient outcomes to intensivist staffing compared cohorts of patients before and after introduction of a closed ICU model.

In 1984, Li et al. [6] analyzed outcomes of patients in a community hospital ICU before (year 1 patients) and after (year 2 patients) introduction of physicians dedicated to ICU patient care. They stratified the year 1 and year 2 patients using severity of illness (need for therapeutic intervention or mental status) and other characteristics (age, location prior to ICU admission, reason for admission), and demonstrated that year 2 patients had significantly lower mortality [odds ratio (OR), 0.62 ; $95 \%$ confidence interval $(\mathrm{CI}), 0.45-0.98$; $P=0.01]$. In addition, they reported that mortality dramatically declined from year 1 to year 2 in patients with congestive heart failure and sepsis.

Subsequently, the results of multiple retrospective cohort studies have demonstrated improvement in mortality, morbidity, and other markers of care improvement [7, 8, 19, 2128]. The weakness of these studies was the use of historical controls. This leaves open the question of whether the improvements in outcome were due to intensivist intervention or simply advances in medicine. One simultaneous cohort analysis by Hanson et al. [9] compared ICU patients cared for by dedicated intensivists versus ICU patients cared for by a group of general surgeons. This study did not demonstrate a difference in mortality, but patients cared for by dedicated intensivists had significantly shorter ICU and hospitals stays, a lower number of mechanical ventilation days, and sustained fewer complications. A variety of studies have shown improved outcomes in specific diseases when ICU management is directed by a dedicated intensivist. Improved outcomes have been documented in acute lung injury [29], moderate to severe trauma [30], abdominal aortic surgery [19], esophageal resection [22], and neurocritically ill patients [31].

In 2002, Pronovost et al. [10] attempting to evaluate the impact of intensivist ICU staffing on patient outcomes performed a systematic review and meta-analysis of 27 observational ICU staffing cohort studies including 27,473 patients. To stratify ICU intensivist staffing by the level of intensivist involvement in patient care, Pronovost et al. [10] introduced the terms "high-intensity staffing" and "low-intensity staffing." High-intensity staffing included ICUs using closed and mandatory intensivist consultation, and low-intensity staffing included elective intensivist consultation and no intensivist involvement. Pronovost et al. pooled the study results to compare 14,356 patients in high-intensity units with 13,117 patients in low-intensity units and found a significant decrease in ICU mortality (pooled estimate relative risk, 0.71; $95 \%$ CI, 0.62-0.82) and hospital mortality (pooled estimate relative risk 0.61; $95 \% \mathrm{CI}, 0.50-0.75)$ in patients receiving care in highintensity units. The study also noted that high-intensity staffing was associated with reduced hospital LOS in ten of 13 studies and reduced ICU LOS in 14 of 18 studies without case mix adjustment. They noted the potential for selection bias in the studies, but felt the results were representative because of the consistent results.

More recently, a study by Levy et al. [32] cast doubt on the benefit of intensivist-driven ICU care. They used the Project Impact database, a large voluntary administrative database developed by the SCCM, to examine the association between intensivist management and patient mortality. The study included 101,832 critically ill patients from 123 ICUs in 100 US hospitals and found that patients cared for by critical care physicians had a $40 \%$ higher risk of mortality than patients cared for by non-critical-care physicians [OR, 1.4, $95 \% \mathrm{CI}, 1.32-1.49, P<0.001)$. This study has many limitations and the findings run counter to a large body of evidence to the contrary, but should still be considered when examining the evidence.

In reviewing the literature, one finds the preponderance of evidence supports the involvement of an intensivist in the care of critically ill patients. The evidence indicates that critically ill patients are better served in an ICU with high-intensity staffing [10]. The weakness of the open model is the diffusion of responsibility, resulting in a lack of coordinated planning. In addition, in the open unit model, conflicting orders and plans from consulting 
services often result in ancillary staff dissatisfaction and ultimately may contribute to suboptimal patient outcomes $[33,34]$. Evidence of improved outcomes with intensivistdriven care has spurred the design of units which allow the intensivist to assume responsibility for the patient and coordinate care.

One of the limitations of "closed" ICU care is the possible alienation of the patient's primary physician. This problem can be mitigated by maintaining open lines of communication and defined modes of transitions in care when transferring patients out of the ICU.

\section{Nighttime Intensivist Staffing}

On the basis of overwhelming evidence, daytime staffing of ICUs with trained intensivists is now strongly endorsed by the Leapfrog Group and the SCCM. Similar to most areas of the hospital, intensivists in many hospitals are present during daylight hours and provide limited weekend daytime coverage, but are not physically in the hospital at night. It has been recognized for decades that patients admitted to the hospital during nighttime and weekend hours have a higher risk of mortality [35]. There is some debate about the cause of this increased mortality. One theory is that there is a higher severity of illness in patients admitted in the nighttime hours. The recognized benefit of intensivist staffing during daytime hours has led for a call for 24-h intensivist staffing of ICUs [36]. At this time, only about $2 \%$ of ICUs provide $24-\mathrm{h}$ dedicated in-house intensivist coverage [17].

The evidence supporting in-house nighttime staffing by dedicated intensivists is less robust than that supporting daytime staffing. A study from the UK used historical controls to compare outcomes in ICU patients after introduction of 24-h intensivist coverage. A decrease in the mortality ratio from 1.11 to 0.81 (95 \% CI 0.55-0.97; $P<0.05$ ) after the change to 24-h intensivist coverage was reported [37].

Banerjee et al. [38] compared costs in cohorts of patients admitted to a medical ICU separated by a change from daytime in-house intensivist staffing to 24-h in-house intensivist staffing. This study specifically noted a reduction in the mean ICU LOS from 3.0 to 2.6 days $(P<0.001)$ after switching to a 24-h intensivist coverage model. To further evaluate the effect of 24-h intensivst coverage, Banerjee et al. separated the patients into daytime and nighttime admissions, and then stratified patients by APACHE III score quartiles. They found that the sickest patients admitted at night were the only group to see an actual reduction in LOS and cost. They also noted an estimated cost saving of US $\$ 10,000$ for each of the sickest patients admitted at night. In this study, the cost of staffing the ICU with nighttime intensivists was completely offset by the savings associated with decreased ICU LOS. It was also noted that staff satisfaction and perceptions of patient safety, education, and unit organization improved with the 24-h staffing model, but there was not a statistically significant reduction in mortality or improvement in patient and family satisfaction [39].

Wallace et al. [40••] used a survey of hospitals included in the APACHE clinical information systems in 2009 and 2010. The respondents included 49 ICUs in 25 hospitals with a total of 65,752 ICU admissions. Data from 12 ICUs with nighttime intensivist staffing (including 14,424 ICU admissions) were compared with data from 37 ICUs without nighttime intensivist staffing (including 51,328 admissions). This study defined nighttime intensivist staffing as an intensivist in the ICU or in the hospital and available for emergencies. This study found that nighttime intensivist staffing was associated with lower mortality $(\mathrm{OR}, 0.62 ; P=0.04)$ in ICUs with low-intensity daytime staffing (optional intensivist consultation model), but there was not a mortality benefit associated with nighttime intensivist coverage in ICUs with high-intensity daytime staffing $(\mathrm{OR}, 1.08 ; P=0.78)$. One significant limitation of this study may be the definition of a nighttime intensivist. For instance, an intensivist with primary responsibility in another area of the hospital, but available for coverage, might confer a very different benefit from that conferred by a dedicated ICU intensivist.

The SCCM and the Leapfrog Group endorse a 24-h intensivist staffing model [41], but this model may be hard to justify financially purely on the basis of a mortality benefit according to the available evidence. In addition, an ongoing shortage of trained intensivists limits the ability of hospitals to convert to 24-h dedicated intensivist coverage [42]. One solution is to stratify the staffing requirements of ICUs on the basis of ICU size and patient acuity, similar to the method used to partition trauma centers [41]. ICUs can be designated into one of three levels, and the intensivist staffing intensity would vary on the basis of the ICU level. ICUs designated as level 1 would have comprehensive care including a dedicated in-house intensivist. ICUs designated as level 2 or 3 would still have daytime intensivist staffing, but off-hours staffing would use critical care "effectors" [43].

"Effectors" or "extenders" may be physicians or allied health care providers who are able to reach ICU patients within $5 \mathrm{~min}$ and are able to discuss patient care issues with an intensivist via the telephone or telemedicine [43]. In many academic hospitals, the physician extender is a resident physician. The Leapfrog quality initiative states that effectors should have completed the SCCM critical care support course [44]. This 2-day course was designed to train the nonintensivist to evaluate and treat the acute deterioration of critically ill patients. At this time, no study has evaluated the effectiveness of this course in lowering mortality or the hospital compliance with this initiative.

The current pool of effectors includes nurse practitioners, physician assistants, hospitalists, and resident physicians. 
Few data exist comparing ICU patient outcomes using different types of care effectors [45]. One limited study compared care practices of nurse practitioners and physician assistants with those of resident physicians and found similar outcomes, but noted that resident physicians cared for older, sicker patients [46]. Multiple other studies have noted that nurse practitioners and physician assistants can be effective in implementing mechanical ventilation weaning protocols [47], and are proficient with ICU procedures [48, 49]. For practical purposes, a limited number of effectors are available to work nights and weekends, so a model may be generated using nurse practitioners, physician assistants, and hospitalists/residents interchangeably. Of course, this assumes that the effectors have been adequately trained to evaluate and treat acute changes in critically ill patients.

\section{Telemedicine}

The desire to improve patient outcomes with intensivistsupervised care has increased the demand for trained ICU physicians. The shortage of physicians in this field has generated a variety of solutions to increase availability of ICU physicians in all ICUs, including remote and smaller ICUs [50]. Theoretical benefits of a telemedicine program include more rapid intervention on alarms and abnormal laboratory values, and a rapid initiation of lifesaving treatment. Telemedicine is rapidly gaining acceptance in the ICU setting as a potential way to adhere to Leapfrog guidelines and gain the benefit of intensivist coverage of the ICU. A variety of versions of the telemedicine platform exist, but most have common features, including video conferencing and electronic monitoring. There are a wide range of telemedicine coverage models, and the level of involvement of the telemedicine service in patient care management differs by institution.

The published evidence supporting telemedicine as a program to increase access to intensivist patient care was initially positive. Grundy et al. [51] reported the first use of telemedicine in the ICU in 1977. This report demonstrated the feasibility of using audiovisual technology to allow remote intensivist consultation. Grundy et al. noted that the technology may be limited by the high cost of the equipment and that some clinical staff at the remotely monitored site had difficulty adapting to remote interactions with ICU practitioners. Rosenfeld et al. [52] conducted a prospective observational study comparing outcomes in patients in an academic-affiliated hospital surgical ICU before and after introduction of a telemedicine program. This ICU had intensivist coverage during the study period in the form of a consultant for $30 \%$ of patients, and in the form of the primary management provider for $5-10 \%$ of patients. In this study, the intervention was telemedicine used $24 \mathrm{~h}$ per day via intensivist coverage from home. The intensivist performed formal rounds or discussed each case with physician staff on a daily basis and discussed each patient with the bedside nurse twice a day. In addition, the intensivist was available for further consultation on an asneeded basis. The researchers compared 201 patients in the 16-week intervention period with patients in two separate 16-week baseline periods consisting of 225 patients in period 1 and 202 patients in period 2. Observed to predicted ratios for mortality decreased by 32 and $58 \%$ from those in period 1 and period 2 after the intervention $(P<0.05)$. In addition, ICU LOS decreased by 26 and $35 \%$ from that in period 1 and period 2 , respectively $(P<0.01)$.

Since these two initial reports, multiple studies have been published examining ICU telemedicine and the impact on mortality and LOS. Most of these studies were reviewed and included in a meta-analysis by Young et al. [53••]. This meta-analysis analyzed 13 studies (including 41,374 ICU patients) which reported data on ICU and inhospital mortality and/or ICU and hospital LOS. Young et al. noted that there was heterogeneity in the study setting, staffing models of the remote sites that were monitored, and the manner in which telemedicine was performed. Use of telemedicine coverage was associated with a reduction in ICU mortality (OR, 0.80; $95 \% \mathrm{CI}$, $0.66-0.97 ; P=0.02$ ) but not in-hospital mortality (OR, $0.82 ; 95 \%$ CI, 0.65-1.03; $P=0.08)$. Telemedicine coverage was associated with a reduction in ICU LOS (mean difference, -1.26 days; $95 \% \mathrm{CI},-2.21$ to -0.30 ; $P=0.01$ ) but not hospital LOS (mean difference, -0.64 ; $95 \% \mathrm{CI},-1.52$ to $0.25 ; P=0.16$ ). One criticism of the studies in this analysis is most of the studies focused on outcomes based on interventions designed to rescue acutely ill patients at night [54]. In addition, there was a lack of randomized controlled studies included in the meta-analysis, although the same could be said of the evidence supporting intensivist-driven ICU care.

In 2011, Lilly et al. [55••] published the results of a prospective ICU telemedicine program implemented in a large academic medical center including 6,290 patients in seven ICUs. They compared ICU/hospital mortality, best practice compliance, rates of preventable complications, and hospital/ICU LOS before and after implementation of the program. In this study, the telemedicine team had full discretion in interventions and patient care (see Table 2). This is in sharp contrast to other studies in which the ICU telemedicine service had a reduced ability to intervene owing to limited physician approval [56]. The hospital mortality rate decreased from 13.6 to $11.8 \%$ (OR, 0.40 ; $95 \%$ CI, $0.31-0.52 ; P=0.005)$ and ICU mortality decreased from 10.7 to $8.6 \%$ (OR, 0.37; $95 \% \mathrm{CI}$, $0.28-0.49 ; \quad P=0.003)$ after implementation of the 
Table 2 Telemedicine ICU interventions in the study by Lilly et al. [55••]

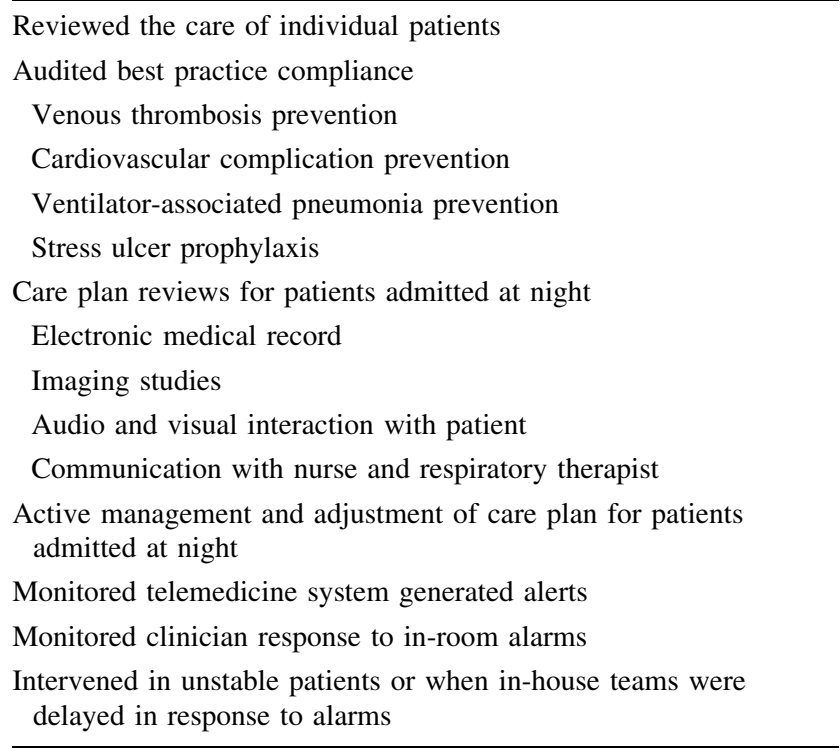

telemedicine program. In addition, significant reductions in hospital and ICU LOS and the incidence of catheter-related bloodstream infections and ventilator-associated pneumonia were noted.

The study by Lilly et al. was unique because the physicians on the telemedicine team were allowed full discretion in patient care. This may have led to more interventions and direction of care [57]. In addition, the telemedicine team was used to ensure compliance with quality improvement guidelines. It is important to recognize that this study was performed in multiple ICUs in one academic center, so further study is required to evaluate this telemedicine practice model in other institutions.

\section{Conclusion}

ICU care is an expensive endeavor. Between 2000 and 2005 annual critical care costs increased by $44 \%$ from US\$56.6 billion to US\$81.7 billion [4]. The number of patients requiring ICU care is expected to continue to increase with the aging of an increasingly multimorbid American population, since the elderly have a disproportionately higher demand for ICU-level care [58]. Controversy still exists regarding the best way to deliver care to critically ill patients. A large body of evidence supports the provision of an intensivist in the care of ICU patients. High-intensity ICU physician staffing is associated with improved outcomes and decreased costs [10]. Increasing financial pressure by organizations such as the Leapfrog Group will incentivize hospitals to consider intensivist staffing models. Closed unit models benefit the patient by providing high-intensity staffing and generating coordinated care plans, but may not be appropriate in all settings. The shortage of trained intensivists is not expected to change soon [59], so it is not feasible to expect all ICUs to use a 24-h in-house dedicated intensivist model. ICU staffing models may use an ICU effector to provide care during the night and at the weekend. In addition, telemedicine ICU coverage models may improve care, but the technology must be applied with a willingness to allow intensivist intervention and direction of care.

Acknowledgments Disclosure Jacob T. Gutsche and Jesse M. Raiten declare no conflict of interest.

\section{References}

Papers of particular interest, published recently, have been highlighted as:

- Of importance

- Of major importance

1. Sherman IJ, Kretzer RM, Tamargo RJ. Personal recollections of Walter E. Dandy and his brain team. J Neurosurg. 2006;105(3): 487-93.

2. Henning JD, Roberts MJ, Sharma D, Hoffman A, Mahoney PF. Military intensive care part 1. A historical review. J R Army Med Corps. 2007;153(4):283-5.

3. Milbrandt EB, Kersten A, Rahim MT, Dremsizov TT, Clermont G, Cooper LM, et al. Growth of intensive care unit resource use and its estimated cost in Medicare. Crit Care Med. 2008;36(9): 2504-10.

4. - Halpern NA, Pastores SM. Critical care medicine in the United States 2000-2005: an analysis of bed numbers, occupancy rates, payer mix, and costs. Crit Care Med. 2010;38(1):65-71. This is an analysis of the trend of hospital and critical bed usage. This report may have limited utility to predict further trends since our population is aging rapidly.

5. Halpern NA, Pastores SM, Greenstein RJ. Critical care medicine in the United States 1985-2000: an analysis of bed numbers, use, and costs. Crit Care Med. 2004;32(6):1254-9.

6. Li TC, Phillips MC, Shaw L, Cook EF, Natanson C, Goldman L. On-site physician staffing in a community hospital intensive care unit. Impact on test and procedure use and on patient outcome. JAMA. 1984;252(15):2023-7.

7. Reynolds HN, Haupt MT, Thill-Baharozian MC, Carlson RW. Impact of critical care physician staffing on patients with septic shock in a university hospital medical intensive care unit. JAMA. 1988;260(23):3446-50.

8. Brown JJ, Sullivan G. Effect on ICU mortality of a full-time critical care specialist. Chest. 1989;96(1):127-9.

9. Hanson CW 3rd, Deutschman CS, Anderson HL 3rd, Reilly PM, Behringer EC, Schwab CW, et al. Effects of an organized critical care service on outcomes and resource utilization: a cohort study. Crit Care Med. 1999;27(2):270-4.

10. Pronovost PJ, Angus DC, Dorman T, Robinson KA, Dremsizov TT, Young TL. Physician staffing patterns and clinical outcomes in critically ill patients: a systematic review. JAMA. 2002; 288(17):2151-62. 
11. Geerts WH, Pineo GF, Heit JA, Bergqvist D, Lassen MR, Colwell $\mathrm{CW}$, et al. Prevention of venous thromboembolism: the Seventh ACCP Conference on Antithrombotic and Thrombolytic Therapy. Chest. 2004;126(3 Suppl):338S-400S.

12. Marik PE, Pastores SM, Annane D, Meduri GU, Sprung CL, Arlt $\mathrm{W}$, et al. Recommendations for the diagnosis and management of corticosteroid insufficiency in critically ill adult patients: consensus statements from an international task force by the American College of Critical Care Medicine. Crit Care Med. 2008;36(6):1937-49.

13. Pronovost PJ, Thompson DA, Holzmueller CG, Dorman T, Rudolph BA. Evaluating the impact of the Leapfrog Groups standard for intensive care unit physician staffing. Semin Anesth Perioper Med Pain. 2005;24(1):50-8.

14. Kohn LT, Corrigan JM, Donaldson MS. To err is human: building a safer health system. Washington: National Academies Press; 2000.

15. Birkmeyer JD, Birkmeyer CM, Wenneberg DE, Young M. Leapfrog safety standards: potential benefits of universal adoption. Washington: Leapfrog Group; 2000.

16. - Morrow DA, Fang JC, Fintel DJ, Granger CB, Katz JN, Kushner FG, et al. Evolution of critical care cardiology: transformation of the cardiovascular intensive care unit and the emerging need for new medical staffing and training models: a scientific statement from the American Heart Association. Circulation. 2012;126(11):1408-28. This article highlights the need to further expand critical care training to include critically ill patients in cardiology care units. In addition, it emphasizes the need for critical care physicians with specific skill sets in superspecialty units.

17. Angus DC, Shorr AF, White A, Dremsizov TT, Schmitz RJ, Kelley MA. Critical care delivery in the United States: distribution of services and compliance with Leapfrog recommendations. Crit Care Med. 2006;34(4):1016-24.

18. Knaus WA, Wagner DP, Zimmerman JE, Draper EA. Variations in mortality and length of stay in intensive care units. Ann Intern Med. 1993;118(10):753-61.

19. Pronovost PJ, Jenckes MW, Dorman T, Garrett E, Breslow MJ, Rosenfeld BA, et al. Organizational characteristics of intensive care units related to outcomes of abdominal aortic surgery. JAMA. 1999;281(14):1310-7.

20. Gutsche JT, Kohl BA. Who should care for intensive care unit patients? Crit Care Med. 2007;35(2 Suppl):S18-23.

21. Samuels O, Webb A, Culler S, Martin K, Barrow D. Impact of a dedicated neurocritical care team in treating patients with aneurysmal subarachnoid hemorrhage. Neurocrit Care. 2011;14(3): 334-40.

22. Dimick JB, Pronovost PJ, Heitmiller RF, Lipsett PA. Intensive care unit physician staffing is associated with decreased length of stay, hospital cost, and complications after esophageal resection. Crit Care Med. 2001;29(4):753-8.

23. Baldock G, Foley P, Brett S. The impact of organisational change on outcome in an intensive care unit in the United Kingdom. Intensive Care Med. 2001;27(5):865-72.

24. Carson SS, Stocking C, Podsadecki T, Christenson J, Pohlman A, MacRae S, et al. Effects of organizational change in the medical intensive care unit of a teaching hospital: a comparison of 'open' and 'closed' formats. JAMA. 1996;276(4):322-8.

25. Ghorra S, Reinert SE, Cioffi W, Buczko G, Simms HH. Analysis of the effect of conversion from open to closed surgical intensive care unit. Ann Surg. 1999;229(2):163-71.

26. Multz AS, Chalfin DB, Samson IM, Dantzker DR, Fein AM, Steinberg HN, et al. A "closed" medical intensive care unit (MICU) improves resource utilization when compared with an "open" MICU. Am J Respir Crit Care Med. 1998;157(5 Pt 1):1468-73.
27. Tai DY, Goh SK, Eng PC, Wang YT. Impact on quality of patient care and procedure use in the medical intensive care unit (MICU) following reorganisation. Ann Acad Med Singapore. 1998;27(3): 309-13.

28. Nathens AB, Rivara FP, MacKenzie EJ, Maier RV, Wang J, Egleston B, et al. The impact of an intensivist-model ICU on trauma-related mortality. Ann Surg. 2006;244(4):545-54.

29. Treggiari MM, Martin DP, Yanez ND, Caldwell E, Hudson LD, Rubenfeld GD. Effect of intensive care unit organizational model and structure on outcomes in patients with acute lung injury. Am J Respir Crit Care Med. 2007;176(7):685-90.

30. MacKenzie EJ, Rivara FP, Jurkovich GJ, Nathens AB, Frey KP, Egleston BL, et al. A national evaluation of the effect of traumacenter care on mortality. N Engl J Med. 2006;354(4):366-78.

31. Suarez JI, Zaidat OO, Suri MF, Feen ES, Lynch G, Hickman J, et al. Length of stay and mortality in neurocritically ill patients: impact of a specialized neurocritical care team. Crit Care Med. 2004;32(11):2311-7.

32. Levy MM, Rapoport J, Lemeshow S, Chalfin DB, Phillips G, Danis M. Association between critical care physician management and patient mortality in the intensive care unit. Ann Intern Med. 2008;148(11):801-9.

33. Carlson RW, Weiland DE, Srivathsan K. Does a full-time, 24-hour intensivist improve care and efficiency? Crit Care Clin. 1996;12(3):525-51.

34. Haut ER, Sicoutris CP, Meredith DM, Sonnad SS, Reilly PM, Schwab CW, et al. Improved nurse job satisfaction and job retention with the transition from a "mandatory consultation" model to a "semiclosed" surgical intensive care unit: a 1-year prospective evaluation. Crit Care Med. 2006;34(2):387-95.

35. Bell CM, Redelmeier DA. Mortality among patients admitted to hospitals on weekends as compared with weekdays. N Engl J Med. 2001;345(9):663-8.

36. Burnham EL, Moss M, Geraci MW. The case for 24/7 in-house intensivist coverage. Am J Respir Crit Care Med. 2010;181 (11):1159-60.

37. Blunt MC, Burchett KR. Out-of-hours consultant cover and casemix-adjusted mortality in intensive care. Lancet. 2000;356(9231): 735-6.

38. Banerjee R, Naessens JM, Seferian EG, Gajic O, Moriarty JP, Johnson MG, et al. Economic implications of nighttime attending intensivist coverage in a medical intensive care unit. Crit Care Med. 2011;39(6):1257-62.

39. Gajic O, Afessa B, Hanson AC, Krpata T, Yilmaz M, Mohamed $\mathrm{SF}$, et al. Effect of 24-hour mandatory versus on-demand critical care specialist presence on quality of care and family and provider satisfaction in the intensive care unit of a teaching hospital. Crit Care Med. 2008;36(1):36-44.

40. • Wallace DJ, Angus DC, Barnato AE, Kramer AA, Kahn JM. Nighttime intensivist staffing and mortality among critically ill patients. N Engl J Med. 2012;366(22):2093-101. This large retrospective analysis of the Acute Physiology and Chronic Health Evaluation clinical information system indicates that nighttime intensivist staffing may only benefit patients in ICUs with lowintensity daytime staffing.

41. Haupt MT, Bekes CE, Brilli RJ, Carl LC, Gray AW, Jastremski MS, et al. Guidelines on critical care services and personnel: recommendations based on a system of categorization of three levels of care. Crit Care Med. 2003;31(11):2677-83.

42. Krell K. Critical care workforce. Crit Care Med. 2008;36(4): 1350-3.

43. Pronovost PJ, Needham DM, Waters H, Birkmeyer CM, Calinawan JR, Birkmeyer JD, et al. Intensive care unit physician staffing: financial modeling of the Leapfrog standard. Crit Care Med. 2004;32(6):1247-53. 
44. Manthous CA. Leapfrog and critical care: evidence- and realitybased intensive care for the 21st century. Am J Med. 2004; 116(3):188-93.

45. Kleinpell RM, Ely EW, Grabenkort R. Nurse practitioners and physician assistants in the intensive care unit: an evidence-based review. Crit Care Med. 2008;36(10):2888-97.

46. Rudy EB, Davidson LJ, Daly B, Clochesy JM, Sereika S, Baldisseri M, et al. Care activities and outcomes of patients cared for by acute care nurse practitioners, physician assistants, and resident physicians: a comparison. Am J Crit Care. 1998;7(4): 267-81.

47. Burns SM, Earven S. Improving outcomes for mechanically ventilated medical intensive care unit patients using advanced practice nurses: a 6-year experience. Crit Care Nurs Clin North Am. 2002;14(3):231-43.

48. Kaups KL, Parks SN, Morris CL. Intracranial pressure monitor placement by midlevel practitioners. J Trauma. 1998;45(5): 884-6.

49. Dubaybo BA, Samson MK, Carlson RW. The role of physicianassistants in critical care units. Chest. 1991;99(1):89-91.

50. Angus DC, Kelley MA, Schmitz RJ, White A, Popovich J Jr. Caring for the critically ill patient. Current and projected workforce requirements for care of the critically ill and patients with pulmonary disease: can we meet the requirements of an aging population? JAMA. 2000;284(21):2762-70.

51. Grundy BL, Crawford P, Jones PK, Kiley ML, Reisman A, Pao YH, et al. Telemedicine in critical care: an experiment in health care delivery. JACEP. 1977;6(10):439-44.

52. Rosenfeld BA, Dorman T, Breslow MJ, Pronovost P, Jenckes M, Zhang $\mathrm{N}$, et al. Intensive care unit telemedicine: alternate paradigm for providing continuous intensivist care. Crit Care Med. 2000;28(12):3925-31.

53. • Young LB, Chan PS, Lu X, Nallamothu BK, Sasson C, Cram PM. Impact of telemedicine intensive care unit coverage on patient outcomes: a systematic review and meta-analysis. Arch Intern Med. 2011;171(6):498-506. This large meta-analysis demonstrated a lack of benefit of ICU telemedicine when used as a measure to rescue patients with acute decompensation. This study questioned the broad application of a complex health intervention without delineation of specific mechanisms to improve care.

54. Kahn JM. Intensive care unit telemedicine: promises and pitfalls. Arch Intern Med. 2011;171(6):495-6.

55. • Lilly CM, Cody S, Zhao H, Landry K, Baker SP, Mcllwaine J, et al. Hospital mortality, length of stay, and preventable complications among critically ill patients before and after tele-ICU reengineering of critical care processes. JAMA. 2011;305(21): 2175-83. This study reported the benefits of ICU telemedicine using specific patient improvement interventions. The intensivists staffing the telemedicine ICU service had full discretion in care and reviewed best practice adherence.

56. Thomas EJ, Lucke JF, Wueste L, Weavind L, Patel B. Association of telemedicine for remote monitoring of intensive care patients with mortality, complications, and length of stay. JAMA. 2009;302(24):2671-8.

57. Kahn JM. The use and misuse of ICU telemedicine. JAMA. 2011;305(21):2227-8.

58. Schmitz RLM, White A. Future needs in pulmonary and critical care medicine. Cambridge: Abt Associates; 1998.

59. HRSA. The critical care workforce: a study of the supply and demand for critical care physicians. Report to Congress. Requested by Senate Report 108-81, The Lewin Group under contract number HRSA-250-01-001, Editor. Washington, DC: US Department of Health and Human Services, Health Resources and Services Administration; 2006. 